\title{
"Os donos do barro": reflexão sobre as artimanhas do capital no Polo oleiro-cerâmico da Região Metropolitana de Manaus
}

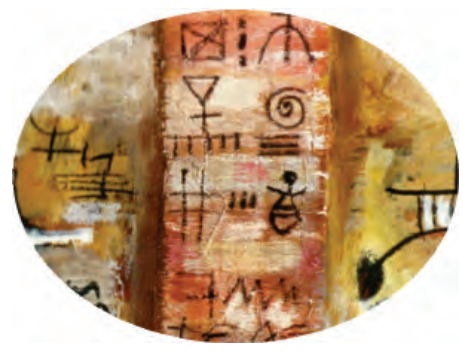

\author{
Cleiton Ferreira Maciel* \\ Maria Izabel de Medeiros Valle ${ }^{* *}$ \\ Jeanne Mariel Brito de Moura*** \\ Allison Santos de Andrade ${ }^{* * * *}$
}

Resumo: $\mathrm{O}$ presente artigo analisa as estratégias do capital sobre o trabalho no Polo oleiro-cerâmico da Região Metropolitana de Manaus (RMM), setor que fabrica $80 \%$ dos tijolos e telhas consumidos no Estado do Amazonas. Essas estratégias estão relacionadas à reorganização do processo global de acumulação do capital a partir das exigências dos novos paradigmas da produção: flexibilidade, inovações organizacionais, novas tecnologias etc. Assim, na primeira parte do trabalho busca-se mostrar a inserção e a importância da produção de tijolos no cenário econômico amazonense. Na segunda parte aborda-se a contribuição sociológica para a compreensão das artimanhas do

\footnotetext{
* Graduado em Ciências Sociais pela Universidade Federal do Amazonas (2010). Atualmente é mestrando do Programa de PósGraduação em Sociologia da mesma universidade (PPGS- UFAM) e membro do grupo de pesquisa "Trabalho e Sociedade na Amazônia". E-mail: cleiton.keto@hotmail.com.

** Doutora em Sociologia e Antropologia pela Universidade Federal do Rio de Janeiro (2000). Professora do Programa de PósGraduação em Sociologia da Universidade Federal do Amazonas. Líder do grupo de pesquisa "Trabalho e Sociedade na Amazônia". E-mail: izabelvalle@ufam.edu.br.

${ }^{* * *}$ Graduada em Ciências Sociais pela Universidade Federal Rural de Pernambuco (2009). Atualmente é mestranda do Programa de Pós-Graduação em Ciências Sociais da Universidade Federal de Campina Grande (PPGCS-UFCG) e membro do grupo de pesquisa "Comunicação, direitos, cidadania e mudanças sociais". E-mail: maribrito21@yahoo.com.br.

${ }^{* * * *}$ Graduado em Ciências Sociais pela Universidade Federal do Amazonas (2010). Atualmente é mestrando do Programa de PósGraduação em Sociologia da mesma universidade (PPGS- UFAM) e membro do grupo de pesquisa "Trabalho e Sociedade na Amazônia". E-mail: allison.andrade21@gmail.com.
} 
capital sobre o trabalho, nos ajudando a compor, assim, a terceira parte do artigo, onde se identificam e problematizam-se os arranjos organizacionais do capital no âmbito oleiro-cerâmico da RMM.

Palavras-chave: Capital; trabalho; olaria; região metropolitana de Manaus; estratégias empresariais.

Abstract: This article analyzes the strategies of capital over labor in the Pottery Pole of the Metropolitan Region of Manaus (RMM), a sector that produces $80 \%$ of bricks and tiles consumed in the state of Amazonas. These strategies are related to the reorganization of the global process of capital accumulation based on the requirements of the new paradigms of manufacturing: flexibility, organizational innovations, new technologies, etc. The first part of this work will show the insertion and the importance of production of bricks in the economic scenario of Amazonas. In the second part we will bring the contribution to the sociological understanding of the wiles of capital over labor, helping us to write, so the third section, where we will identify and problematize the organizing ways of capital in the Pottery Pole of the RMM.

Keywords: Capital; work; pottery; metropolitan region of Manaus; business strategies.

\section{Introdução}

Desde o início da década de 1990 a Amazônia tem sido palco de intensas transformações no setor produtivo vinculadas a uma nova divisão internacional do trabalho. No bojo dessas mudanças desencadeadas, sobretudo, por um arranjo reestruturativo da economia capitalista, observa uma onda de introdução de práticas globais de organização do trabalho que são dadas como "receitas" aos países que buscam adentrar os portões da globalização.

172 Somanlu, ano 11, n. 1, jan./jun. 2011 
As ciências humanas e, em especial, a sociologia têm voltado os olhos para essa nova economia global, percebendo que começa a desenhar-se no horizonte um cenário produtivo transnacional, cuja principal característica é ignorar os espaços territoriais tradicionais, imprimindo nestes uma lógica de produção vinculada à ordem mundial de acumulação do capital. Trabalhos como o de Silva (1997), Valle (2007), Castro (2009), Oliveira (2007) e Seráfico (2011) vêm acompanhando e problematizando essas questões no âmbito local, contudo, vinculando seu modus operandis ao macro espaço da produção capitalista, qual seja, a "multidimensionalidade" da globalização e sua trama de relações sociais que estruturam a configuração global do capitalismo (SERÁFICO, 2011).

Nesse novo desenho da produção capitalista são configuradas práticas produtivas que não mais estão circunscritas ao espaço local; pelo contrário, emergem elementos e estratégias de organização do mundo do trabalho, que, por seu turno, fazem parte dos arranjos do atual desenvolvimento do capitalismo: a mundialização do capital.

Tendo em vista essa perspectiva da organização do capitalismo em âmbito global, qual uma teia produtiva mundial da nova divisão internacional do trabalho, esse artigo discutirá como se configuram as estratégias do capital em um contexto específico do global: o Polo oleiro-cerâmico da Região Metropolitana de Manaus. Nesse sentido, apontaremos, primeiramente, o papel que a produção de tijolos e telhas desempenha do cenário econômico brasileiro e, em particular, no estado do Amazonas. Em seguida, faremos uma discussão teórica sobre a moderna organização do capitalismo, tendo em vista a compreensão das artimanhas do capital sobre o trabalho dentro do processo de mundialização do capital. Essa discussão nos ajudará a problematizar aquilo que trataremos na etapa final desse artigo, qual seja, as estratégias empresariais em uma olaria da Região Metropolitana de Manaus.

\section{A produção de tijolos e telhas no cenário nacional e regional}

A produção de cerâmica vermelha (tijolos e telhas) constitui-se em umas das principais atividades econômicas dentro do cenário produtivo bra- 
sileiro, tendo em vista a sua participação fundamental na movimentação do mercado da construção civil nacional. Trata-se de um setor produtivo com diversas cerâmicas espalhadas pelos estados brasileiros, e que produz anualmente cerca de 2,5 bilhões de peças. Contudo, diante da existência de um mercado consumidor que por razões históricas é o maior do Brasil, a concentração nacional das indústrias ceramistas está localizada na região sudeste (ANICER, 2010).

Em face dessa configuração da indústria ceramista nacional, a região Norte emerge como um importante ator dentro desse cenário de fabricação de tijolos e telhas, tendo uma participação considerável na produção mensal, a qual está estimada em 114 milhões de peças e que gera, segundo dados do Sebrae, cerca de 10 mil empregos diretos e indiretos (SEBRAE, 2010).

No que diz respeito ao estado do Amazonas, a produção de cerâmica vermelha está concentrada nos municípios de Manacapuru e Iranduba, os quais fazem parte da Região Metropolitana de Manaus. Entretanto, este último, tradicionalmente apresenta-se como o principal pólo oleiro-cerâmico do estado, com um total de 25 olarias instaladas e associadas a Aceram. Segundo Trindade (1999), esta concentração deve-se à relação de proximidade que o município tem em relação à capital amazonense. Acresce-se a isso, segundo o autor, a grande disponibilidade de argila de alta qualidade que é a principal matéria-prima desse ramo de atividade econômica. Outro fator que contribuiu para que Iranduba se tornasse o maior produtor de cerâmica vermelha do Amazonas, foi o não pagamento de ICMS ) quando do ingresso do produto na cidade de Manaus, principal mercado consumidor da produção oleira amazonense.

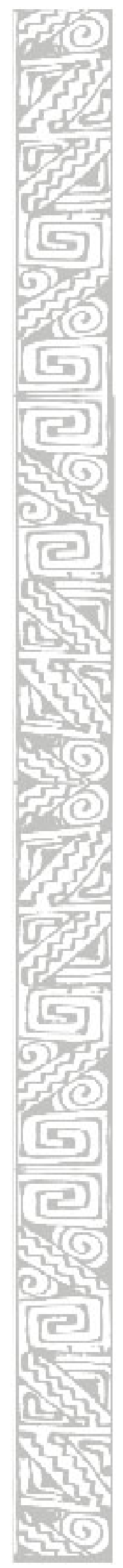

174 Somanlu, ano 11, n. 1, jan./jun. 2011 

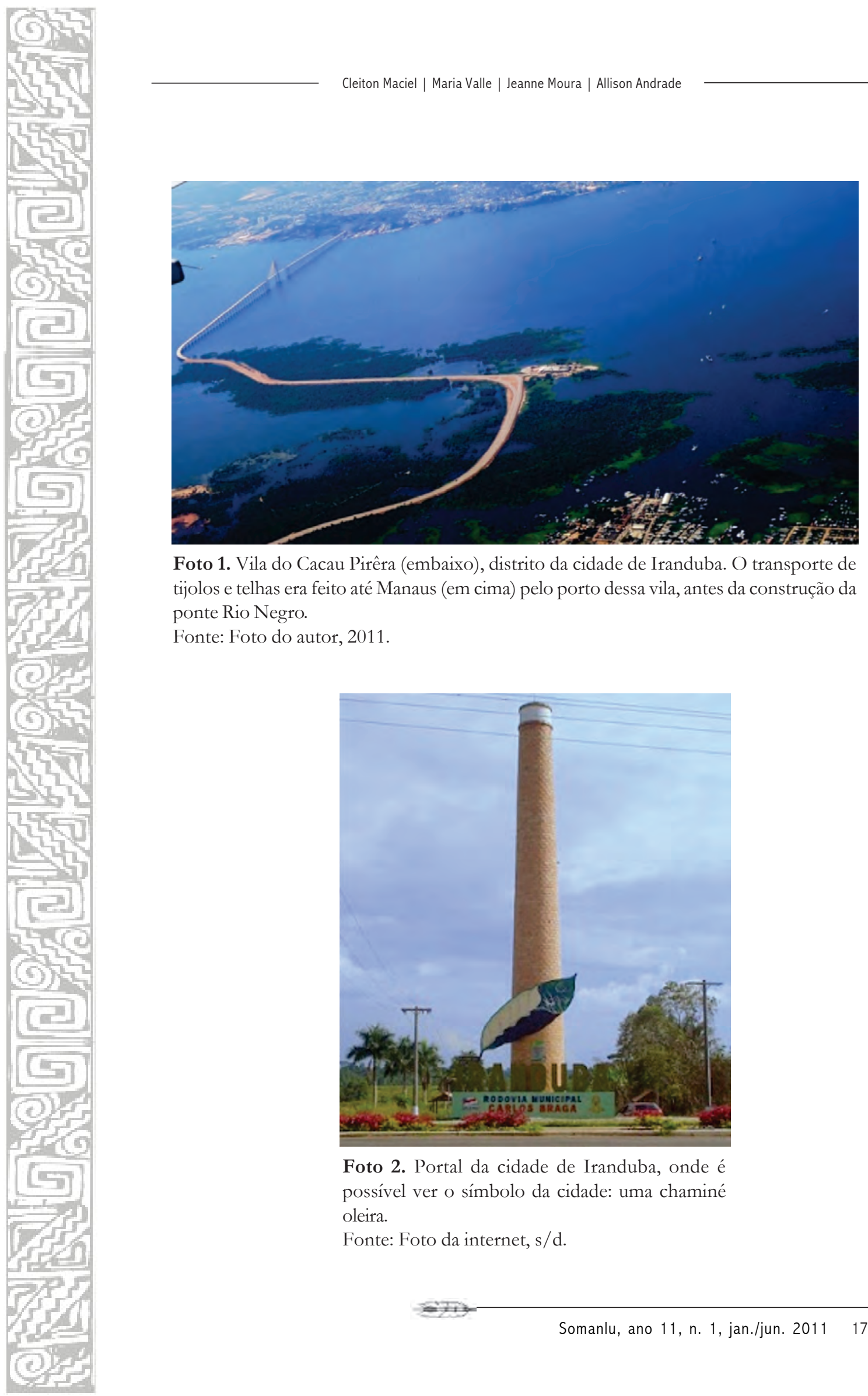

Foto 1. Vila do Cacau Pirêra (embaixo), distrito da cidade de Iranduba. O transporte de tijolos e telhas era feito até Manaus (em cima) pelo porto dessa vila, antes da construção da ponte Rio Negro.

Fonte: Foto do autor, 2011.

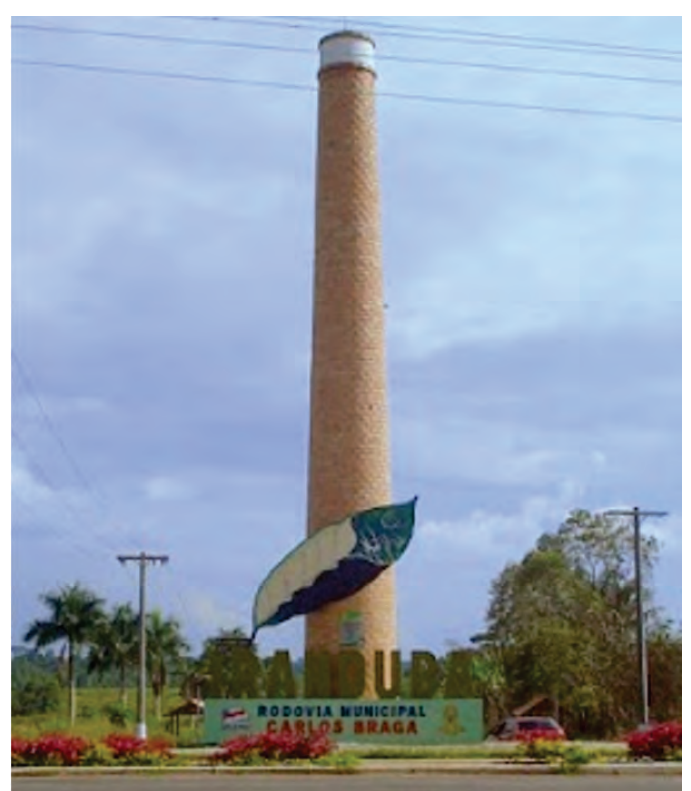

Foto 2. Portal da cidade de Iranduba, onde é possível ver o símbolo da cidade: uma chaminé oleira.

Fonte: Foto da internet, s/d. 
A primeira fábrica de tijolos do município de Iranduba data de 1946, época em que a cidade ainda era distrito de Manaus, tendo sido pioneira a Cerâmica Marajó, que ainda hoje opera na fabricação desse tipo de produto. Em 10 de dezembro de 1981, a Vila de Iranduba tornou-se um município autônomo, sendo elevada a categoria de cidade do mesmo nome.

Em um primeiro momento, o município teve sua base econômica centrada no setor primário, como o cultivo de hortaliças, criação de bovinos de corte e de leite e cultivo de frutos (ABREU, 2004). Contudo, com a expansão imobiliária ocorrida em meados dos anos 80 por conta do estímulo dado à construção civil através do Sistema Financeiro de Habitação, ocorreu uma explosão na demanda por produtos da indústria oleira-cerâmica, fazendo com que os empresários de Manaus passassem a vislumbrar uma oportunidade de obter lucros no emergente mercado imobiliário, e iniciassem um processo de investimento na aquisição de terrenos e máquinas para a instalação de novas indústrias ceramistas no município de Iranduba (CHAVES, 2001).

Hoje, o município de Iranduba é responsável por cerca de $80 \%$ de toda a produção de cerâmica vermelha do Estado do Amazonas, o que representa em termos quantitativos, aproximadamente 10 milhões de tijolos por mês (ACERAM, 2012). Além disso, o Polo Oleiro-Cerâmico de Iranduba movimenta, em média, $80 \%$ da construção civil amazonense, gerando no município, cerca de 2.000 empregos diretos e indiretos e abrangendo um total de 6.000 trabalhadores, entre prestadores de serviço e fornecedores (ACERAM, 2012).

\section{As olarias da Região Metropolitana de Manaus: crise e rearranjo industrial}

O início dos anos 2000 marca o cenário oleiro amazonense como um período crítico na estrutura produtiva desse ramo industrial. A lenha nativa era a matéria-prima usada nos fornos de queima de tijolos, sendo que a maioria das empresas comprava esse material dos pequenos produtores rurais, os quais não tinham permissão dos órgãos ambientais para desmatar, transportar e vender a madeira às olarias. Nesse período era comum ver caminhões com a carroceria cheias de "toras" de árvores semi-queimadas, uma vez que grande

176 Somanlu, ano 11, n. 1, jan./jun. 2011 
parte dessa lenha provinha dos roçados localizados nas proximidades do Pólo oleiro-cerâmico.

Em face da chamada "crise ambiental" que vem forjando a atual conjuntura mundial de leis de proteção ao meio ambiente, esses órgãos ambientais, como Ibama e Ipaam passaram a realizar uma série de operações tendo em vista a fiscalização contínua do transporte ilegal de lenha pelas estradas dessa região amazônica, bem como o acompanhamento por satélite das áreas desmatadas no entorno das olarias.

Tratava-se, assim, de um momento fulcral dentro da organização produtiva oleira-cerâmica, ou seja, buscava-se mudar a base de material de queima de tijolos, sinalizando às agencias de proteção ambiental o interesse em enquadrarse na lógica do "desenvolvimento sustentável" ou continuava-se a operar do modo "tradicional", constituindo-se, portanto, em empresas ilegais dentro de um cenário de pressão ambiental não apenas local, mas, sobretudo, global.

No bojo dessas metamorfoses em curso na Amazônia, às olarias voltaram-se à primeira plataforma de mudanças, qual seja, implementar uma agenda de alterações na configuração produtiva que, por um lado, desse conta de responder positiva e satisfatoriamente aos interesses dos órgãos ambientais nacionais e globais, e, por outro lado, fosse cômodo à reprodução dos interesses dos empresários do setor oleiro.

As condições propícias ao desenvolvimento de uma política organizacional que favorecesse diversos agentes foram forjadas por meio da ação do próprio Estado, tendo o Sebrae como a força transformadora da engrenagem que se tinha até aquele momento. O que haveria de ser realizado se constituiria, assim, não em uma ruptura com as práticas produtivas do passado, mas em uma fase de transição cômoda rumo a um modelo "moderno" de organização industrial, onde os diversos interesses e forças em jogo teriam suas demandas atendidas, ainda que em níveis diferenciados. Em trabalho recente denominei esse processo como "simbiose do capital" (MACIEL e VALLE, 2010).

A alteração macro-organizacional teve como momento inicial a formação de uma estrutura burocrática dentro do próprio Sebrae que ficou res- 
ponsável pela elaboração de uma agenda de políticas produtivas as quais seriam introduzidas, primeiramente, nas três maiores empresas oleiras da cidade de Iranduba. Nesse sentido, não se romperia radicalmente com a base produtiva anterior, caracterizada pela queima substancial de lenha. A transição seria lenta, gradual, tendo em vista o papel que a indústria oleira representa no cenário da construção civil manauense, em franca expansão desde meados da década de 2000.

Essa transição teve como desenho central uma plataforma de políticas organizacionais protagonizada pelo empresariado oleiro, que, por seu turno, fazem parte do movimento estratégico do capital sobre o trabalho. Portanto, faz necessário problematizar aqui como esse processo histórico-dialético vem sendo debatido pela sociologia, de sorte que nos forneça ferramentas conceituais no sentido de compreender as singularidades e as implicações das artimanhas produtivas do capital no Polo oleiro-cerâmico da Região Metropolitana de Manaus. É o que será feito a seguir.

\section{As artimanhas do capital no bojo da relação capital-trabalho}

A partir dos anos de 1980 lança-se sobre a teia produtiva global uma série de inovações tecnológicas - a década de 1980 é conhecida na Sociologia do Trabalho como "a década das inovações capitalistas" - que tinham como elemento norteador a busca pela flexibilização. Essa torna-se a palavra-chave para superar os entraves gerados no seio do modelo fordista de produção. Isso implicou, principalmente em um novo padrão de organização do trabalho, denominado modelo Toyotista de produção, o qual assumiu como traços fundamentais do processo produtivo os métodos just-in-time / Kan-ban e CCQ's, a racionalização da produção e uma nova divisão internacional do trabalho (HARVEY, 1993).

A divisão internacional do trabalho consistiu, com efeito, na valorização de determinados capitais na medida em que se estabelecia um novo padrão tecnológico onde o capital mais valorizado era aquele associado ao conhecimento (SERÁFICO, 2011). Os países desenvolvidos formaram a “divi-

178 Somanlu, ano 11, n. 1, jan./jun. 2011 
são superior" e buscaram concentrar a cadeia produtiva na fabricação de bens de alto valor agregado, ou seja, aqueles produtos que necessitam do uso intenso de tecnologia de ponta para serem fabricados. $\mathrm{Na}$ "divisão inferior" localizaram-se os chamados "países emergentes", que assumiram o papel de fornecedores de produtos de baixa ou média intensidade tecnológica.

O discurso pregado pela lógica toyotista é que a sobrevivência dessas empresas em um cenário de maior competição internacional vinculava-se à capacidade de fabricar novos produtos mais especializados e de elevada qualidade dentro de novos processos produtivos. A tônica discursiva do Toyotismo tem como baluarte, portanto, a ideia de que a configuração produtiva das empresas precisa ser, cada vez mais, flexível; em uma palavra, com os ouvidos atentos aos delineamentos da cultura do consumo.

Nessas empresas, a relação entre capital e trabalho passa a configurarse, assim, como uma espécie de "horizontalização" das relações, onde se transfere para o trabalhador o peso das incertezas do mercado. Em face disso, o trabalhador precisa ser portador de qualidades que são exigidas pelas empresas desse "novo" momento da organização do trabalho, como: espírito de colaboração, vontade de trabalhar em equipe e disposição em ser, constantemente, "aperfeiçoado" (LIMA, 2007). O que acontece, de fato, é aquilo que vem sendo denominado como o trabalho polivalente e multifuncional, tendo em vista que, dentro da retórica empresarial, possuindo essas qualidades do mundo do trabalho, cada trabalhador passa a ser um "gerente" ou, mais usualmente conhecido, um "colaborador" (VALLE, 2007).

Logo, a organização do trabalho baseia-se na "desespecialização" dos trabalhadores, tornando-os "plurioperadores". Trata-se, portanto, de confrontar o saber do trabalhador qualificado através da multifuncionalidade produtiva, o que, por seu turno, diminui seu poder sobre a produção e aumenta a intensidade do trabalho.

A lógica reinante dentro da perspectiva toyotista de produção se assenta, pois, nessa macro ideia de flexibilização que apresenta, concretamente, sua manifestação micro sobre o trabalhador coletivo (MARX, 1985). Assim, a organização do trabalho, baseada na flexibilização do próprio conjunto de tra- 
balhadores propicia ao capital se beneficiar de uma totalidade de mão-deobra, na medida em que se tenta motivar os "colaboradores" a produzir mais e com mais vigor.

Nestes termos, o Toyotismo tem no trabalhador coletivo sua grande força de dinamização do capital em face de um grande número de trabalhadores atuando juntos e coordenadamente, daí se pregar de forma intensiva a colaboração entre os trabalhadores, o "espírito de equipe", etc. De fato, dentro dessa perspectiva de cooperação entre a mão-de-obra floresce um maior ganho ao capitalista tendo em vista a diminuição do tempo de trabalho exigido à realização de uma atividade proposta (ANTUNES, 2010).

No bojo dessa conjuntura produtiva, as empresas multinacionais desenvolvem técnicas de gestão e de organização desse trabalhador coletivo na tentativa de, por um lado, extrair uma maior produtividade, possibilitando maiores taxas de lucros e, por outro lado, tornar o trabalhador coletivo cada vez mais individual, num paradoxo produtivo inerente ao sistema capitalista.

Em uma palavra, quando se trata de perseguir os objetivos centrais do "modelo japonês" - produtividade e qualidade - as empresas buscam ter o trabalhador coletivo enquanto unidade matizada, colocando-o como parte fundamental do "espírito" da empresa. Contudo, quando se trata da organização dos trabalhadores enquanto classe, a lógica toyotista procura fazê-los se auto enxergarem como unidades autônomas, sem interesses coletivos à margem dos interesses da empresa (ANTUNES, 2005).

No âmago dessa configuração observa-se, assim, uma maior dependência do trabalhador coletivo em relação à empresa. Esta, por seu turno, busca substituir a própria ação sindical por meio da negociação direta entre trabalhadores e gerência, sem passar pela via dos sindicatos. A ideia das empresas é desconfigurar o papel da organização dos trabalhadores enquanto sujeitos autônomos e com objetivos próprios. Em face disso, mobilizam recursos para manter o trabalhador coletivo cada vez mais envolvido com a empresa. Em uma palavra, pretende-se inculcar que os interesses da empresa são os mesmos interesses dos trabalhadores, fortalecendo, nessa direção, o poder de negociação do próprio capital (VALLE, 2007).

180 Somanlu, ano 11, n. 1, jan./jun. 2011 
Essa é a lógica: fomentar aparatos da organização produtiva para se ter o Estado de bem-estar social dentro da própria empresa. Aquilo que Marx (1998) fazia referência no que diz respeito ao entendimento de que a fábrica é um espaço de lutas e de resistência por excelência, é, com efeito, invertido dentro da perspectiva toyotista. A fábrica não é um local onde se desenvolve a dominação, mas um espaço de cooperação, sem luta pela hegemonia.

Nesses termos, é possível pensar que o Toyotismo caracteriza-se, portanto, pela radicalização da própria racionalização capitalista que tem como afinidade eletiva, segundo Weber (2004), a ética protestante do século XVI. Weber (2004) observa que o processo de racionalização das empresas capitalistas modernas ocorre a partir de um controle contábil dos custos, das formas racionais de organização do trabalho e da mecanização.

Assim, as transformações engendradas no seio das empresas capitalistas modernas envolvem uma ação social que visa excluir os indivíduos do controle sobre os meios de produção, impondo uma estrutura de organização burocrática que, por seu turno, procuram manter certa ordem de "regras calculáveis" dentro do processo de fabricação (WEBER, 1982).

Dentro dessa lógica, as várias esferas do mundo do trabalho são racionalizadas. A radicalização dessa racionalização se dá, no atual estágio do capitalismo globalizado, em face da captura da subjetividade do operário. Esse é o ponto fundamental. O que queremos dizer é que, concretamente, o modelo que convencionou-se chamar de Toyotismo se diferencia do Fordismo, sobretudo, na capacidade de operar, em um nível micro, indo de encontro às motivações das ações dos trabalhadores.

Quando Weber (1982) postulou o conceito de ação social, o autor buscava entender e interpretar o sentido das ações para explicá-las, sociologicamente, em seu desenvolvimento e significado. Dessarte, o objetivo da sociologia em Weber seria compreender as ações dotadas de sentido, observando as suas regularidades. Nestes termos, a ação social seria uma ação que carrega um significado subjetivo, o qual motivaria o agir do sujeito em uma relação social.

Sob a égide da reestruturação produtiva e da globalização, o capital busca capturar, exatamente, o sentido da ação do sujeito, na medida em que 
formula estratégias de controle do trabalho na fábrica. Assim, emerge como elemento fundamental da lógica toyotista, sobre a qual o pensamento de Weber nos ajuda a refletir, o fazer com que a ação dos trabalhadores tenha um sentido único, um fim pré-determinado: a busca de ganhos para a empresa.

Desse modo, o Toyotismo visa descomplexificar a ação social do operário, dotando-a de um sentido que esteja em consonância com os ideais globais da acumulação do capital. Em suma, lança suas garras sobre a subjetividade que motiva a ação do trabalhador, objetivando-a na cooperação deste para com a produtividade nas empresas.

Em um nível macro, a racionalização, a qual Weber faz referência, torna-se uma racionalidade global na era da globalização. Está em curso a burocratização do mundo (IANNI, 1995). A flexibilização, portanto, envolve a racionalidade radicalizada. Todos os padrões tradicionais de produção são colocados em xeque em face de uma objetivação universal do Toyotismo, como se o capital tivesse descoberto o seu "segredo" de ampliação e reprodução. Daí Alves (1999, p. 86) afirmar que:

(...) No decorrer dos anos 80, ele tenderia a assumir um valor universal surgindo como "produção enxuta" - a lean production uma nova racionalidade do capital em sua etapa de mundialização. (...) Deste modo, a categoria da flexibilidade é algo intrínseco à produção capitalista, surgindo, ainda em seus primórdios, quando o capital instaurou o trabalho assalariado das condições de vida, a separação do trabalhador de seus meios de produção, a separação ente o "caracol e sua concha".

Assim, o processo de reestruturação produtiva mostra-se como uma nova configuração no mundo globalizado, onde se tem como elemento fundamental a mundialização do capital. Introduz-se, dessa forma, uma nova dinâmica nas relações industriais, na configuração das políticas sobre o trabalho, nos contratos e na qualificação dos trabalhadores. A organização do trabalho passa a estar vinculada ao pragmatismo empresarial da lógica produtivista e da qualidade. Aparece, nestes termos, a figura do "colaborador", aquele que "faz parte do espírito da empresa".

182 Somanlu, ano 11, n. 1, jan./jun. 2011 
Esse processo se desenvolve em diferentes locais do mundo, e não seria inconcebível se falar do "mundo nos locais". Por seu turno, Iranduba constitui-se enquanto esse local mundial onde a essência da acumulação do capital ganha forma e substancialidade; onde arranjos produtivos locais são transformados e redesenhados. Em uma palavra, onde se torna observável sociologicamente o estabelecimento de determinados constrangimentos do capital sobre o trabalho. É o que buscaremos problematizar a seguir.

\section{Estratégias empresariais no mundo do trabalho oleiro da Região Metro- politana de Manaus}

Como falamos no inicio do artigo, foi o Sebrae que "selecionou" três empresas oleiras para que fossem pioneiras na introdução de novas tecnologias dentro da estrutura produtiva oleira. No planejamento delineado, esse conjunto de elementos industriais seria implementado em outras olarias à medida que fosse se estabelecendo uma nova cultura organizacional no ramo oleirocerâmico da Região Metropolitana de Manaus (MACIEL e VALLE, 2010).

As empresas iniciaram, dessa forma, um processo de reorganização do trabalho, estabelecendo metas de produtividade, busca por qualidade e controle do processo produtivo. Uma dessas formas de racionalização do trabalho diz respeito à adoção de inovações organizacionais de origem japonesa, como os Círculos de Controle de Qualidade (CCQ).

$\mathrm{Na}$ empresa onde nossa pesquisa foi efetuada os trabalhadores em conjunto com a liderança se reuniam de 15 em 15 dias, formando, assim, um CCQ. Era nessas reuniões efetuadas dentro do período de trabalho dos funcionários que os líderes e "colaboradores" avaliavam a execução de cada etapa do projeto e traçavam as novas metas a serem alcançadas pela empresa, mapeando todas as etapas do processo de fabricação.

Nosso interesse em mostrar os resultados dessa pesquisa está em trazer a lume a perspectiva de que as estratégias empresariais vinculam-se a uma nova forma de organização da produção, e que, portanto, remete a uma onda de reordenamentos industriais a fim de estabelecer parâmetros de racionalização produtiva tendo em vista o controle do capital sobre o trabalho. 
O primeiro desses reordenamentos diz respeito à própria contratação dos trabalhadores que preenchem o quadro de funcionários da olaria. A partir da adoção das inovações organizacionais e da emergência da ideia de que o trabalho em equipe é o cerne do ganho de produtividade, a cerâmica passou a estabelecer uma política de contratação baseada no critério comportamental do trabalhador. Assim, passou-se a ter como estratégia empresarial a adoção de critérios de seleção da força de trabalho que levem em conta a capacidade do trabalhador em ser participativo, cooperador, responsável e compromissado com os objetivos da empresa (MACIEL e VALLE, 2010).

Esse processo de contratação tem em vista uma espécie de domesticaşão do trabalho, uma vez que na filosofia empresarial da cerâmica pesquisada os trabalhadores que possuem estas "qualidades" estão aptos a se envolverem com maior afinco às tarefas determinadas pelo Círculo de Controle de Qualidade.

Nesse contexto, portanto, a subjetividade do trabalhador adquire papel chave na estrutura organizativa do setor oleiro, e mostra-se enquanto objeto analítico-explicativo fundamental por se apresentar como uma das artimanhas do capital para exercer o controle sobre o trabalho, buscando o comprometimento do trabalhador para com as metas produtivas traçadas pela empresa.

O segundo reordenamento é concernente à introdução dos Círculos de Controle de Qualidade na empresa. Fazer reuniões dentro do período de trabalho fez parte de uma estratégia para mostrar que o trabalhador tem a centralidade na empresa. Assim sendo, a introdução dos CCQs buscou aprofundar a extração do trabalho, capturando a força de trabalho não somente no plano técnico, mas na própria subjetividade do trabalhador. Pretende-se, dessa forma, "envolver" o operário com a política organizacional da empresa, seja oferecendo cursos sobre a importância da qualidade, seja introduzindo a bonificação como um modo de mostrar para o trabalhador que ele é "peça fundamental".

Nessa perspectiva, o discurso da cerâmica passa a estar voltado para a ideia de que os ganhos da empresa giram em torno do trabalho feito em equipe, no qual todos precisam de todos, formando um corpo produtivo bem ajustado. Destarte, aflora-se a "pedra de toque" da ação empresarial moderna

184 Somanlu, ano 11, n. 1, jan./jun. 2011 
(VALLE, 2007), ou seja, a filosofia de que o que mobiliza a empresa na adoção dessas inovações é a valorização do ser humano, introduzindo, em face disso, o espírito de cooperação entre trabalhador e empresa.

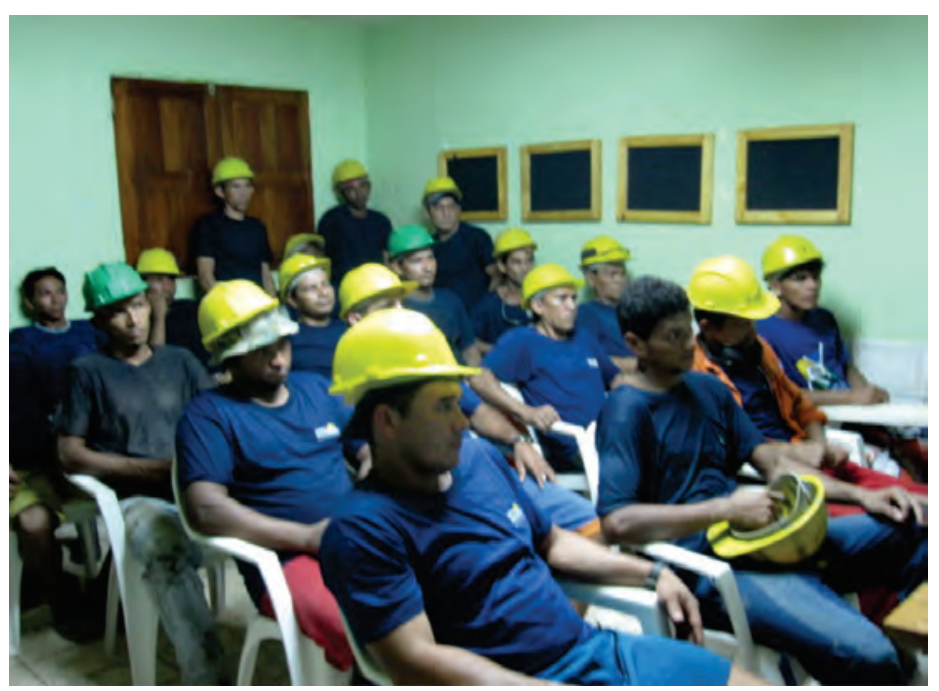

Foto 3. Reunião do Círculo de Controle de Qualidade.

Fonte: Foto do autor, 2010.

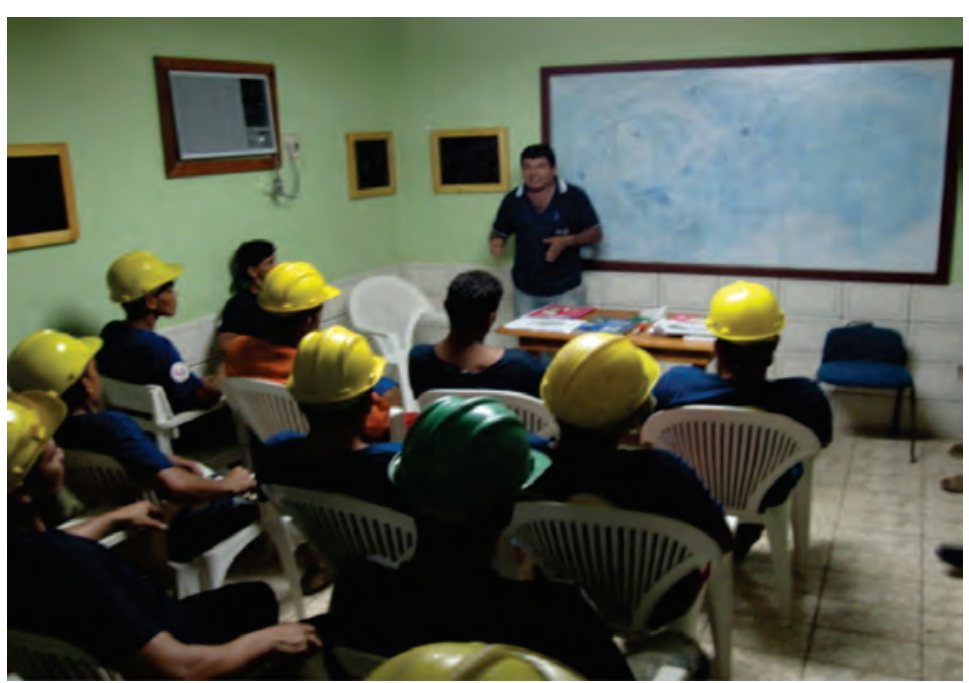

Foto 4. Os "colaboradores" recebendo treinamento da gerência da olaria. Fonte: Foto do autor, 2010. 
Dito de outra forma, a artimanha do capital visa a postular a ideia de que, mais do que um mero trabalhador, o "homem do barro" é um colaborador. Isso traz implicações importantes na relação capital-trabalho, uma vez que no cerne desse discurso empresarial ancora-se a perspectiva de que o trabalhador está sendo peça fundamental na formulação de um projeto de empresa. A empresa não se constituiria, nesse sentido, enquanto um espaço de contradição entre os possuídos e despossuídos dos meios de produção, mas enquanto um espaço de convergência de interesses, tanto dos trabalhadores quanto dos empresários.

A ideia, portanto, é fazer com que o trabalhador veja que ele colabora na construção desse "segundo lar", e, assim sendo, precisa estar disposto a oferecer não apenas os membros do corpo ao trabalho, mas ter o sentido de seu trabalho voltado para o "espírito" da empresa, qual seja, a busca incessante do lucro.

O terceiro reordenamento diz respeito à responsabilidade atribuída ao trabalhador no que concerne à gestão da produção. Fluxogramas (Foto 5) e croquis (Foto 6) indicando como se deve proceder em cada máquina ou que não fazer em determinado processo são espalhados pela fábrica, como uma tentativa de controle invisível sobre as etapas da produção.

Podemos dizer que nessa organização da produção de tijolos em Iranduba, o papel de supervisionar a produção, ou de inspecionar as etapas do processo de fabricação sai do plano tradicional, para uma dimensão do trabalho flexível, onde o inspetor não existe, mas está "bem ali”, em cada canto do chão da fábrica, criando, assim, uma mentalidade favorável à concentração no trabalho, e estabelecendo o não-desperdício com distrações e fantasias.

186 Somanlu, ano 11, n. 1, jan./jun. 2011 

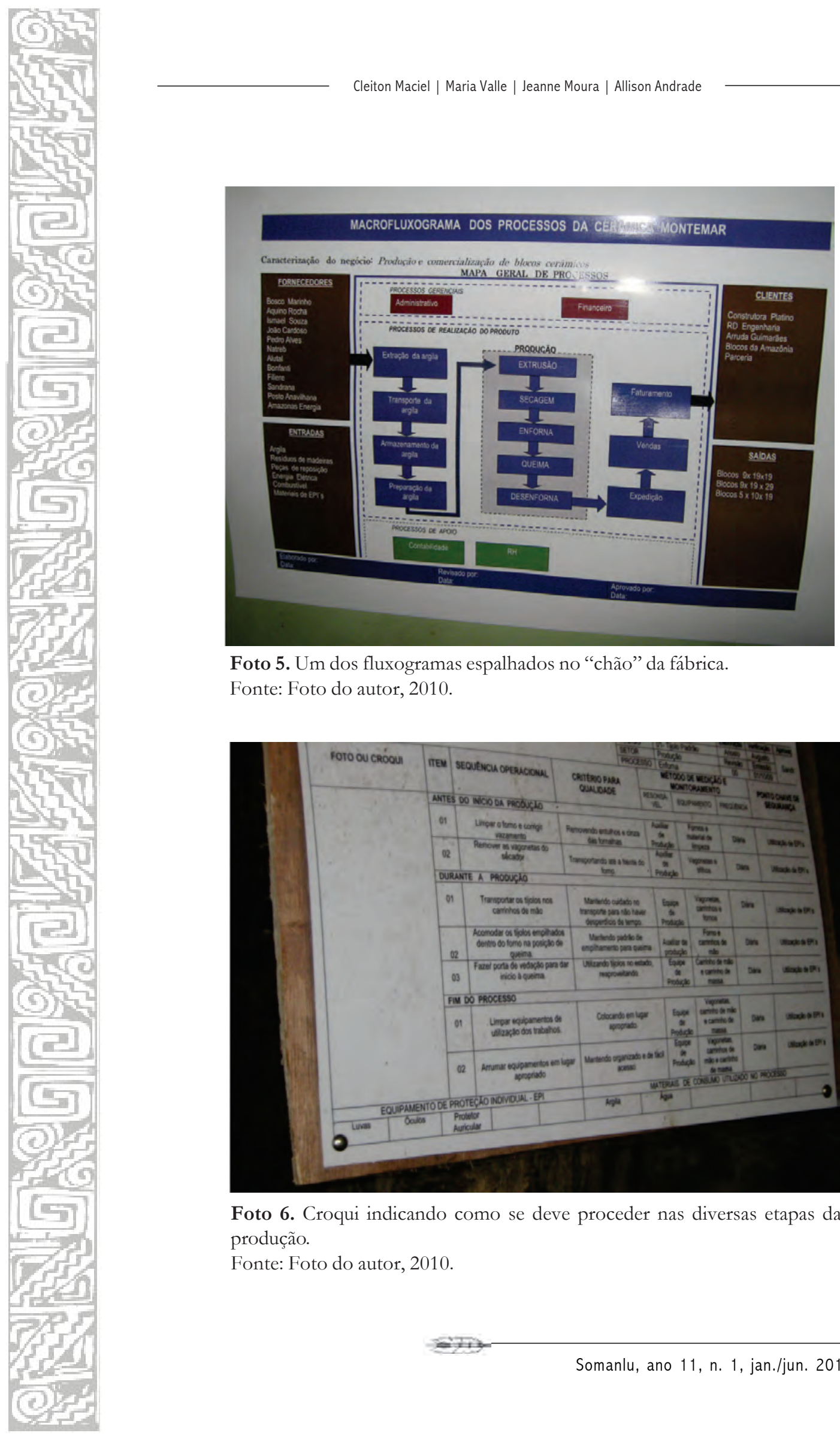

Foto 5. Um dos fluxogramas espalhados no "chão" da fábrica.

Fonte: Foto do autor, 2010.

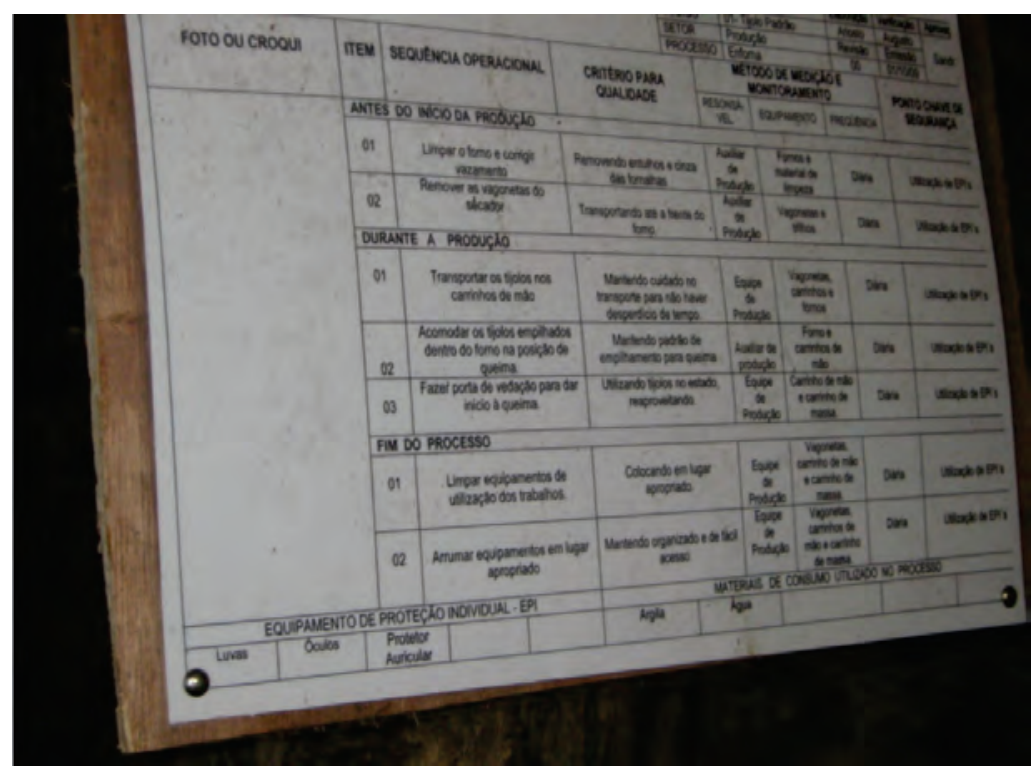

Foto 6. Croqui indicando como se deve proceder nas diversas etapas da produção.

Fonte: Foto do autor, 2010.

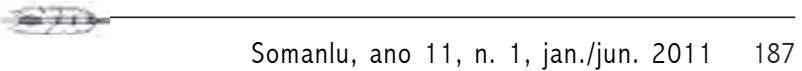


O quarto reordenamento refere-se ao papel que a busca por ISOs (International Organization for Standardization.) adquire na transição produtiva em curso. Trata-se de uma exigência global que visa unificar e padronizar comportamentos produtivos. Quando uma empresa persegue a certificação dada pela ISO, ela precisa cumprir algumas cláusulas estabelecidas em parâmetros internacionais de normas fabris (MACIEL e VALLE, 2010). Uma dessas cláusulas se refere ao processo em que as auditorias exigem que os trabalhadores demonstrem conhecimento sobre os procedimentos de diversas etapas da produção de determinado bem.

Logo, cada procedimento necessário para a integração entre qualidade e produtividade precisa estar articulado no processo de produção, constituindo-se, assim, numa forma de criar mecanismos de controle do trabalho, fixando metas a serem alcançadas a cada mês, avaliando os resultados da produção nas reuniões quinzenais, em face de uma visão sistemática e racional sobre os ganhos e perdas na produção.

\section{Considerações finais}

A proposta deste artigo foi fazer uma breve discussão acerca das estratégias empresariais no mundo oleiro da Região Metropolitana de Manaus, observando, assim, que as transformações ora em curso dão conta da incorporação de um "capitalismo moderno" e sua consequente relação com o trabalho de indivíduos que, até então, tinham um modo de vida baseado no cultivo de mandioca, guaraná e pesca de subsistência.

Esse choque de racionalidades é característico dentro da formação econômica capitalista, onde determinadas práticas sociais são alvo das artimanhas do "processo civilizador" do capital. No bojo dessas transformações, as "teias do capital" vêem o trabalho enquanto um objeto de enlaçamento social privilegiado em face da sua capacidade fundante da organização não apenas da produção, mas também da própria constituição da sociedade (ANTUNES, 2009).

188 Somanlu, ano 11, n. 1, jan./jun. 2011 
Dito de outra forma, a reprodução ampliada do capital desenvolve-se buscando romper as especificidades do trabalho local, tendo em vista a estruturação de uma nova totalidade histórico-social que possa reproduzir os ditames das forças globais dominantes. Contudo, essas forças são dinamizadas de formas distintas em distintos lugares dessa infovia mundial. Trata-se, portanto, de um movimento dialético entre capital e arranjos do trabalho específicos, nos quais se desenrolam certas práticas político-econômicas. Em outras palavras, uma contradição latente e ao mesmo tempo obscura que instiga à pesquisa sociológica.

Podemos dizer, nesse sentido, que as inovações organizacionais, bem como a busca por certificações internacionais ISO 9000 e 14000, são frutos das artimanhas do capital sobre o trabalho, onde se ancora a reestruturação produtiva. A própria pressão ambiental por parte dos órgãos governamentais em relação à queima de lenha nativa diz respeito à agenda internacional sobre as mudanças do clima. Interesses globais e interesses de um empresariado local entram, destarte, em cena, negligenciando as formas específicas de produção e reprodução da vida. São estratégias quem visam estabelecer parâmetros produtivos globais em uma indústria local, com o discurso da valorização do trabalhador e de um "novo momento do Pólo oleiro-cerâmico", escondendo, assim, a busca pelo controle do capital sobre o trabalho.

Nas reuniões dos Círculos de Controle de Qualidade realizadas quinzenalmente, por exemplo, não são discutidas temáticas que envolvam diretamente o real interesse dos trabalhadores do setor oleiro, como jornada de trabalho, salários e condições de trabalho. Nesses meetings são tratados os problemas da empresa que dizem respeito à busca pela qualidade e produtividade. Não há espaço para a discussão em torno da questão da própria adoção das inovações tecnológicas, ou seja, se elas são uma estratégia de organização industrial que realmente precise ser ancorada às empresas do setor oleirocerâmico de Iranduba.

Nas entrevistas realizadas, os trabalhadores se queixavam relatando que passavam a maior parte do seu tempo na olaria, e que quando chegavam em casa já estavam muito cansados, sem disposição, portanto, para o conví- 
vio com a família ou para realizarem práticas de subsistência, como pesca, caça ou cultivo de algum tubérculo. Esse quadro ainda é agravado pelo fato da extensão do trabalho oleiro nos fins de semana. Como as olarias "pagam dobrado" pelo dia de trabalho aos sábados e domingos, é comum ver trabalhadores que, em face da oportunidade de se obter um dinheiro a mais, estendem os dias dentro do trabalho também nos fins de semana. Nas palavras de um desses "homens do barro": " (...) como o pagamento mensal é pouco, a gente tem que sacrificar um pouco da família para ganbar um dinheiro a mais" (Pesquisa de campo, 20. nov. 2010).

É esse o processo em que o capital visa extirpar as experiências dos indivíduos enquanto sujeitos em circunstancias históricas singulares, buscando, dessarte, anular suas "narrativas" de vida, seu modo de organização do tempo dentro e além da fábrica, estabelecendo mecanismos de comprometimento do "colaborador" para com o projeto de empresa da qual ele é "parte" substancial.

O que se observa é uma lógica que tem como proposição a microuniversalização de ideais produtivos mundiais, e que assumem, portanto, contornos pragmáticos no setor oleiro, ou seja, a tentativa de organizar os trabalhadores em torno da empresa, não em torno se si mesmos. O número, por exemplo, de pessoas que podem participar das reuniões do Círculo de Controle de Qualidade é definido pela gerência, ou seja, uma decisão vertical que visa horizontalizar resoluções tomadas pelo próprio setor administrativo, embora o discurso seja de que "não existe hierarquia na empresa".

A hierarquia fica invisível uma vez que, no plano descritivo, o trabalhador passa a ter uma maior participação nas decisões da empresa enquanto um projeto. Contudo, num plano analítico é mais razoável pensar na ideia de uma concentração sistemática do controle que busca tornar invisível a hierarquia característica do processo de acumulação capitalista entre força de trabalho e donos dos meios de produção. O processo de hierarquização é refeito, redesenhado. O que se muda não é a estrutura hierárquica, mas a forma como se mostra a organização produtiva, de sorte que a "valorização" do trabalhador não caracteriza o fim da hierarquia, e sim uma nova forma de enevoar as velhas relações entre capital e trabalho.

190 Somanlu, ano 11, n. 1, jan./jun. 2011 


\section{Referências}

ABREU, Suelen. A empresa oleiro-cerâmica do município de Iranduba. Monografia, Faculdade de Estudos Sociais da Universidade Federal do Amazonas, 2004. ACERAM (Associação dos Ceramistas do Estado do Amazonas). Relatório da APL de Base Mineral: "Central de Resíduos", 2012.

ALVES, Giovanni Antonio Pinto. Reestruturação produtiva e crise do sindicalismo no Brasil / Giovanni Antonio Pinto Alves. Campinas, SP [s.n], 1998.

ANICER (Associação Nacional da Indústria Cerâmica) - Curso: "A implantação de controles para melhoria da qualidade de produto cerâmico". Rio de Janeiro, 2010.

ANTUNES, Ricardo. Adeus ao trabalbo?: ensaio sobre as metamorfoses e a centralidade do mundo do trabalho / Ricardo Antunes - 14. ed. - São Paulo: Cortez, 2010.

- Os sentidos do trabalho: ensaio sobre a afirmação e a negação do trabalho / Ricardo Antunes. - [2. ed., 10. reimpre. ver. e ampl.] - São Paulo, SP : Boitempo, 2009.

. O caracol e sua concha: ensaios sobre a nova morfologia do trabalho / Ricardo Antunes - São Paulo: Boitempo, 2005.

CASTRO, Edna. Org. Cidades na Floresta. São Paulo: Annablume, 2008.

CHAVES, Saile Wastran Queiroz. Estudo de Mercado da Produção de tijolos no Município de Iranduba. Monografia, Faculdade de Estudos Sociais da Universidade Federal do Amazonas, 2001.

HARVEY, David. Condição Pós-Moderna. Do fordismo à acumulação flexível. São Paulo: Loyola, 1993.

IANNI, Octavio. Estado e Capitalismo. São Paulo, Brasiliense, 2004. A sociedade global. Rio de Janeiro: Civilização Brasileira, 1992. 
LIMA, Jacob Carlos. Ligações perigosas: trabalho flexível e trabalho associado / Organização de Jacob Carlos Lima. São Paulo: Annablume, 2007.

MACIEL, Cleiton Ferreira; VALLE, Maria Izabel de Medeiros. As inovações tecnológicas no Polo oleiro-cerâmico de Iranduba-Am: um estudo de caso. Universidade Federal do Amazonas. Programa Institucional de Bolsa de Iniciação Científica. Relatório Final. Manaus, 2010.

MARX, Karl. O capital: crítica da economia política / Karl Marx; apresentação de Jacob Gorender; coordenação e revisão de Paul Singer; tradução de Regis Barbosa e Flávio R. Kothe. 2. ed. São Paulo: Nova Cultural, 1985.

. O manifesto comunista. Karl Marx; Friedrich Engels. São Paulo, SP: Paz e Terra, 1998.

OLIVEIRA, Selma Suely Baçal de. A "periferia" do capital: na cadeia produtiva de eletroeletrônicos / Selma Suely Baçal de Oliveira. - Manaus: Editora da Universidade Federal do Amazonas, 2007.

SEBRAE (Serviço Brasileiro de Apoio às Micro e Pequenas Empresas). Manual para a Indústria de Cerâmica Vermelha; redução dos desperdícios e maior eficiência no setor: Fascículo 1/ Roberto Segundo Enrique Castro Tapia. 2. ed. atual e aum. Rio de Janeiro: Sebrae/RJ, 2010.

SERÁFICO, Marcelo. Globalização e empresariado: estudo sobre a Zona Franca de Manaus / Marcelo Bastos de Assis Carvalho. São Paulo: Annablume, 2001.

SILVA, Marilene C. da. Metamorfoses da Amazoônia. Tese (Doutorado). São Paulo: Departamento de Ciências Sociais/IFCH/Unicamp. 1997. Mimeo.

TRINDADE, Pedro. Análise do desempenho da economia oleiro-cerâmica do município de Iranduba. Monografia, Faculdade de Estudos Sociais da Universidade Federal do Amazonas, 1999.

VALLE, Izabel. Globalização e reestruturação produtiva: um estudo sobre a produção offshore em Manaus / Izabel Valle. - Manaus: Editora da Universidade Federal do Amazonas, 2007.

192 Somanlu, ano 11, n. 1, jan./jun. 2011 
WEBER, Max. Economia e Sociedade: fundamentos da sociologia compreensiva / Max Weber; tradução de Regis Barbosa e Karen Elsabe Barbosa; Revisão técnica de Gabriel Cohn - Brasília: Editora da Universidade de Brasília, 2004. Ensaios de Sociologia. Max Weber. Rio de Janeiro: LTC, 1982. 